\title{
GATA5 loss-of-function mutations associated with congenital bicuspid aortic valve
}

\author{
LIN-MEI SHI $^{1}$, JU-WEI TAO ${ }^{1}$, XING-BIAO QIU ${ }^{2}$, JUAN WANG $^{3}$, FANG YUAN $^{2}$, LEI XU $^{2}$,

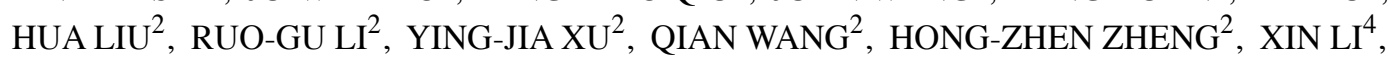 \\ XIAO-ZHOU WANG ${ }^{5}$, MIN ZHANG ${ }^{2}$, XIN-KAI QU $^{2}$ and YI-QING YANG ${ }^{2,6,7}$ \\ ${ }^{1}$ Department of Ultrasonics, Shanghai Pulmonary Hospital, Tongji University School of Medicine, Shanghai 200433; \\ ${ }^{2}$ Department of Cardiology, Shanghai Chest Hospital, Shanghai Jiao Tong University, Shanghai 200030; \\ ${ }^{3}$ Department of Cardiology, East Hospital, Tongji University School of Medicine, Shanghai 200120; \\ Departments of ${ }^{4}$ Extracorporeal Circulation, ${ }^{5}$ Cardiac Surgery, ${ }^{6}$ Cardiovascular Research Laboratory and \\ ${ }^{7}$ Central Laboratory, Shanghai Chest Hospital, Shanghai Jiao Tong University, Shanghai 200030, P.R. China
}

Received November 12, 2013; Accepted March 11, 2014

DOI: $10.3892 /$ ijmm.2014.1700

\begin{abstract}
Bicuspid aortic valve (BAV) is the most common form of congenital cardiovascular defect in humans worldwide and is responsible for substantial morbidity and mortality. Accumulating evidence has demonstated that genetic risk factors are involved in the pathogenesis of BAV. However, BAV is genetically heterogeneous and the genetic basis underlying BAV in a large number of patients remains unknown. In the present study, the coding regions and splice junction sites of the GATA5 gene, which codes for a zinc-finger transcription factor crucial for the normal development of the aortic valve, was sequenced initially in 110 unrelated patients with BAV. The available relatives of the mutation carriers and 200 unrelated healthy individuals used as controls were subsequently genotyped for GATA5. The functional effect of the mutations was characterized by using a luciferase reporter assay system. As a result, two novel heterozygous GATA5 mutations, p.Y16D and p.T252P, were identified in two families with autosomal dominant inheritance of BAV, respectively. The variations were absent in 400 control chromosomes and the altered amino acids were completely conserved evolutionarily. Functional assays revealed that the two GATA5 mutants were
\end{abstract}

Correspondence to: Dr Ju-Wei Tao, Department of Ultrasonics, Shanghai Pulmonary Hospital, Tongji University School of Medicine, 507 Zhengmin Road, Shanghai 200433, P.R. China E-mail: tao_juwei@sina.cn

Dr Yi-Qing Yang, Departments of Cardiology, Cardiovascular Research Laboratory and Central Laboratory, Shanghai Chest Hospital, Shanghai Jiao Tong University, 241 West Huaihai Road, Shanghai 200030, P.R. China

E-mail: yang99yang66@hotmail.com

Key words: congenital heart disease, bicuspid aortic valve, genetics, transcription factor, GATA5, reporter gene associated with significantly reduced transcriptional activity compared with their wild-type counterpart. To the best of our knowledge, this is the first study on the association of GATA5 loss-of-function mutations with enhanced susceptibility to BAV, providing novel insight into the molecular mechanism involved in human BAV and suggesting a potential role for the early prophylaxis and personalized treatment of this common congenital heart disease.

\section{Introduction}

Bicuspid aortic valve (BAV) is the most common form of congenital heart disease in humans, with an estimated prevalence of $0.5-2 \%$ in the general population as well as a pronounced male predominance of $\sim 3: 1$ (1-6). While BAV can occur in isolation, it is frequently associated with other congenital cardiovascular malformations, such as coarctation of the aorta, interruption of the aorta, ventricular septal defect, atrial septal defect, patent ductus arteriosus and hypoplastic left heart syndrome, leading to a wide spectrum of clinical presentations ranging from severe disorder detected in utero to asymptomatic condition in old age (7). Patients with BAV are at high risk for the development of severe complications, including aortic valve regurgitation, aortic valvular stenosis, aortic dilation or even aneurysm, aortic dissection, thrombus formation, and infective endocarditis (8-11). BAV accounts for $70-85 \%$ of aortic stenosis in pediatric patients and at least $50 \%$ of stenotic aortic valve in adults $(12,13)$. Moreover, individuals with BAV have an 8-fold increased risk of aortic dissection and 25 -year risk of valve replacement of $53 \%$, aneurysm formation of $26 \%$ and aortic surgery of $25 \%$ (14). Therefore, BAV confers a heavier burden of disease than all other congenital cardiac lesions combined $(3,7)$. Despite its high prevalence and significant clinical importance, the underlying pathogenic basis of BAV remains largely unclear.

Cardiac valve morphogenesis occurring early in fetal development is a complex and dynamic process that requires the temporal and spatial cooperation of cardiac cell 
commitment, differentiation, proliferation, and migration, and both environmental and genetic risk factors may interrupt this biological process, resulting in abnormal valvulogenesis and the formation of BAV $(15,16)$. Mounting evidence suggests that genetic defects play an important role in the pathogenesis of BAV (7,13). Previous studies have established the substantial familial clustering of $\mathrm{BAV}$, with a prevalence ranging from 9 to $24 \%$ in the first-degree relatives of BAV patients and a heritability as high as $89 \%$, suggesting a Mendelian pattern of inheritance $(7,13)$. By genome-wide scan of the available family members with polymorphic microsatellite markers and linkage analysis, BAV-susceptibility loci have been mapped on chromosomes 9q34-35, 18q, 5q15-21 and 13q33-qter, and NOTCH1 has been identified as the first culprit gene accountable for BAV in the genomic region of 9q34 (17,18). Moreover, candidate gene strategy has led to the identification of various novel mutations in the NOTCHl gene that are associated with BAV (19-21). Additionally, mutations in other genes, including $K C N J 2, T G F B R 2$ and $N K X 2-5$, were detected in patients with BAV (22-24). Nevertheless, BAV is of pronounced genetic heterogeneity and the genetic determinants underpinning BAV in a large number of patients remain to be determined.

GATA5 was reported to have a crucial role in cardiovascular development and valvular morphogenesis (25-31), and the targeted deletion of GATA5 in mice resulted in partially penetrant BAV (31). Furthermore, the endocardial cell-specific inactivation of GATA5 led to BAV, similar to that observed in GATA5-null mice (31). GATA5 is a zinc finger-containing transcription factor that belongs to a subgroup of the GATA family of DNA binding proteins, which, together with GATA4 and GATA6, is abundantly expressed in various mesodermand endoderm-derived tissues, predominantly in embryonic heart $(32,33)$. In humans, mutations in GATA5 have been found to be associated with a wide variety of congenital cardiovascular anomalies, including ventricular and atrial septal defect, tetralogy of Fallot, double outlet right ventricle, aortic stenosis, and BAV (21,34-39). Taken together, these findings suggested screening GATA5 for mutations in another cohort of patients with BAV.

\section{Materials and methods}

Study population. A cohort of 110 unrelated patients with BAV was recruited from the Chinese Han population for this study. The available relatives of the index patients carrying the identified GATA5 mutations were also enlisted. Patients underwent clinical evaluation that included individual and familial histories, medical records, complete physical examination, 12-lead electrocardiogram, and two-dimensional transthoracic echocardiography with color flow Doppler. BAV was confirmed by imaging and/or direct view during aortic valve replacement surgery. Familial BAV was defined if two or more affected relatives had proven BAV. The patients with known chromosomal abnormalities or syndromic cardiovascular defects, such as Marfan syndrome, Turner syndrome, and Di George syndrome, were excluded from the study.

A total of 200 unrelated, ethnically matched healthy individuals randomly selected from the subjects undergoing routine physical examinations were used as controls. In terms of medical histories and echocardiographic records, the control individuals had no congenital cardiovascular deformities. The ethnic origin of a participant was determined by a combination of self-reported ethnicity and a personal questionnaire regarding birthplace, language, religion, and ancestry.

Peripheral venous blood samples were obtained from BAV cases and control individuals. The study protocol conforms to the principles outlined in the Declaration of Helsinki and was approved by the local Institutional Ethics Committee. Written informed consent was obtained from all participants or their guardians prior to study.

Mutational screening of GATA5. Genomic DNA from each participant was extracted from blood lymphocytes with a Wizard Genomic DNA Purification kit (Promega, Madison, WI, USA). The coding regions and flanking introns of the GATA5 gene were sequenced initially in 110 unrelated patients with BAV, and subsequently in the available relatives of the index patients carrying identified mutations and the 200 unrelated, ethnically-matched healthy individuals. The primer pairs used to amplify the coding exons and exon/ intron boundaries of GATA5 by polymerase chain reaction (PCR) were described previously (39). PCR was performed using HotStar Taq DNA Polymerase (Qiagen GmbH, Hilden, Germany) on a Veriti Thermal Cycler (Applied Biosystems, Foster, CA, USA), with standard conditions and concentrations of reagents. The amplified products were analyzed on $1 \%$ agarose gels stained with ethidium bromide and purified with QIAquick Gel Extraction kit (Qiagen GmbH). Both strands of each PCR product were sequenced with a BigDye ${ }^{\circledR}$ Terminator v3.1 Cycle Sequencing kit (Applied Biosystems) under an ABI PRISM 3130 XL DNA Analyzer (Applied Biosystems). The sequencing primers were the same as previously designed for specific region amplifications. The DNA sequences were viewed and analyzed with the DNA Sequencing Analysis Software v5.1 (Applied Biosystems). The variant was validated by resequencing an independent PCR-generated amplicon from the subject and met our quality control thresholds with a call rate of $>99 \%$. Additionally, an identified sequence variation was searched in the single-nucleotide polymorphism (SNP) database at the National Center for Biotechnology Information (http://www. ncbi.nlm.nih.gov/), the human gene mutation (HGM) database (http://www.hgmd.org/), and the 1000 genome database (http://www.1000genomes.org/) to confirm its novelty.

Alignment of multiple GATA5 protein sequences among species. Multiple GATA5 protein sequences across various species were aligned using the online program of MUSCLE, version 3.6 (http://www.ncbi.nlm.nih.gov/).

Prediction of the pathogenic potential of a GATA5 sequence variation. The disease-causing potential of a GATA5 sequence variation was predicted by MutationTaster (an online program at http://www.mutationtaster.org), which automatically gave a probability for the variation to be either a pathogenic mutation or a benign polymorphism. Notably, the P-value used here is the probability of the correct prediction rather than the probability of error as used in t-test statistics (i.e., a value close to 1 indicates a high 'security' of the prediction). Additionally, the 
online program PolyPhen-2 (http://genetics.bwh.harvard.edu/ $\mathrm{pph} 2 /$ ) was used to predict the possible impact of an amino acid substitution on the structure and function of GATA5 protein.

Plasmids and site-directed mutagenesis. The recombinant expression plasmid pcDNA3.1-hGATA5 was constructed as described previously (39). The atrial natriuretic factor (ANF)-luciferase reporter gene, which contains the 2600-bp 5 '-flanking region of the $A N F$ gene, i.e., ANF(-2600)-Luc, was kindly provided by Dr Ichiro Shiojima, from the Department of Cardiovascular Science and Medicine, Chiba University Graduate School of Medicine, Chuo-ku, Chiba, Japan. The identified mutation was introduced into the wild-type GATA5 using a QuickChange II XL Site-Directed Mutagenesis kit (Stratagene, La Jolla, CA, USA) with a complementary pair of primers. The mutant was sequenced to confirm the appropriate mutation and to exclude any other sequence variations.

Reporter gene assay. HEK-293 cells were cultured in Dulbecco's modified Eagle's medium supplemented with $10 \%$ fetal calf serum and seeded in 12-well plates prior to transfection. The ANF(-2600)-Luc reporter construct and an internal control reporter plasmid pGL4.75 (hRluc/CMV, Promega) were used in the transient transfection assay to evaluate the transcriptional activity of the GATA5 mutants. HEK-293 cells were transfected with $0.4 \mu \mathrm{g}$ of wild-type or mutant pcDNA3.1-hGATA5 expression vector, $0.4 \mu \mathrm{g}$ of ANF(-2600)-Luc reporter construct, and $0.04 \mu \mathrm{g}$ of pGL4.75 control reporter vector using a PolyFect Transfection Reagent (Qiagen). For cotransfection experiments, $0.2 \mu \mathrm{g}$ of wild-type pcDNA3.1-hGATA5 together with $0.2 \mu \mathrm{g}$ of mutant pcDNA3.1-hGATA5 or $0.2 \mu \mathrm{g}$ of empty pcDNA3.1 vector were used in the presence of $0.4 \mu \mathrm{g}$ of ANF(-2600)-Luc and $0.04 \mu \mathrm{g}$ of pGL4.75. Firefly and Renilla luciferase activities were measured with the Dual-Glo ${ }^{\circledR}$ luciferase assay system (Promega) $48 \mathrm{~h}$ after transfection. The activity of the ANF promoter was presented as fold activation of Firefly luciferase relative to Renilla luciferase. A minimum of three independent experiments were performed for wild-type and mutant GATA5.

Statistical analysis. Data are expressed as means \pm standard deviation. Continuous variables were tested for normality of distribution, and the Student's unpaired t-test was used to compare the numeric variables between the two groups. Comparison of the categorical variables between the two groups was completed by using Pearson's $\chi^{2}$ test or Fisher's exact test when appropriate. A two-tailed P-value $<0.05$ was considered to indicate statistical difference.

\section{Results}

Clinical characteristics of the study subjects. A cohort of 110 unrelated patients with BAV was enrolled and clinically evaluated as well as 200 unrelated control individuals. All the participants had no established environmental risk factors for congenital heart disease, such as maternal illness and drug use in the first trimester of pregnancy, parental smoking, and long-term exposure to toxicants and ionizing radiation. The baseline clinical characteristics of the 110 unrelated BAV cases are shown in Table I.
Table I. Clinical characteristics of the 110 unrelated patients with bicuspid aortic valve (BAV).

\begin{tabular}{lc} 
Parameter & Statistic \\
\hline Age (years) & $45.4 \pm 11.8$ \\
Male gender (\%) & $72(65.5)$ \\
Positive family history (\%) & $36(32.7)$ \\
Abnormal valve function $^{\mathrm{a}}(\%)$ & $73(66.4)$ \\
Concomitant aortopathy $^{\mathrm{b}}(\%)$ & $67(60.9)$ \\
Concomitant other $^{\text {cardiac structural defects }}{ }^{\mathrm{c}}(\%)$ & \\
Atrial fibrillation $(\%)^{\text {Surgical repair }(\%)}$ & $20(18.2)$ \\
\hline
\end{tabular}

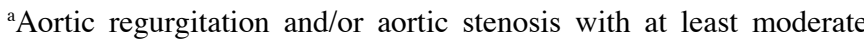

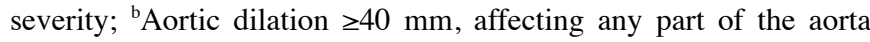
from sinus of Valsalva to proximal descending aorta; 'Seven patients with coarctation of the aorta $(\mathrm{CoA})$; three with ventricular septal defect (VSD); three with patent ductus arteriosus (PDA); two with atrial septal defect (ASD); one with patent formamen ovale; one with anomalous origin of the left coronary artery; one with CoA and VSD; one with CoA and ASD; one with CoA, VSD and PDA.

GATA5 sequence variation. Two heterozygous GATA5 sequence variations were identified in 2 of 110 unrelated BAV patients, respectively, with a mutational prevalence of $\sim 1.82 \%$. Specifically, a change of thymine into guanine at the first nucleotide of codon 16 of the GATA5 gene (c.46T $>$ G), predicting the transition of tyrosine into aspartic acid at amino acid position 16 (p.Y16D), was identified in the index patient from family 1 . A substitution of cytosine for adenine in the first nucleotide of codon 252 (c.754A $>$ C), equivalent to the replacement of threonine by proline at amino acid 252 (p.T252P), was identified in the proband from family 2. The sequence electropherograms showing the identified heterozygous GATA5 variations in contrast to corresponding control sequences are shown in Fig. 1. A schematic diagram of GATA5 protein showing the structural domains and the locations of the detected mutations is shown in Fig. 2. The variations were not observed in the 400 control chromosomes or found in the SNP, HGM and 1,000 genome databases, which were consulted again on November 10, 2013.

A genetic scan of the family members of the mutation carriers showed that in each family, the variation was present in all the affected family members available, but absent in the unaffected family members examined. Analysis of the pedigrees revealed that the variations cosegregated with BAV with complete penetrance. The pedigree structures of the two families are shown in Fig. 3. In addition, in family 1, the proband's father (I-1) and brother (II-3) had ventricular septal defect, aortic stenosis and the electrocardiogram documented atrial fibrillation. In family 2 , the proband's father (I-1) also had aortic stenosis. The phenotypic characteristics and results of genetic screening of the affected pedigree members are listed in Table II. 
Table II. Phenotypic characteristics and status of the GATA5 mutations of the affected pedigree members.

\begin{tabular}{|c|c|c|c|c|}
\hline \multicolumn{3}{|c|}{ Subject information } & Phenotypes & \multirow{2}{*}{$\frac{\text { Genotypes }}{\text { GATA5 mutations }}$} \\
\hline Identity & Gender & Age (years) & Congenital cardiac structural defects & \\
\hline Family 1 & & & & Y16D \\
\hline $\mathrm{I}-1$ & M & $61^{\mathrm{a}}$ & BAV, VSD, AS & NA \\
\hline II-3 & M & 48 & BAV, VSD, AS & $+/-$ \\
\hline II-6 & $\mathrm{F}$ & 45 & BAV & $+/-$ \\
\hline III-3 & $\mathrm{M}$ & 19 & BAV & $+/-$ \\
\hline Family 2 & & & & $\mathrm{~T} 252 \mathrm{P}$ \\
\hline $\mathrm{I}-1$ & M & $55^{\mathrm{a}}$ & $\mathrm{BAV}, \mathrm{AS}$ & NA \\
\hline II-1 & M & 42 & BAV & $+/-$ \\
\hline III-1 & $\mathrm{F}$ & 16 & BAV & $+/-$ \\
\hline
\end{tabular}

${ }^{\mathrm{a}}$ Age at death. M, male; F, female; BAV, bicuspid aortic valve; VSD, ventricular septal defect; NA, not available or not applicable; AS, aortic stenosis; +, presence of mutation; -, absence of mutation.

A

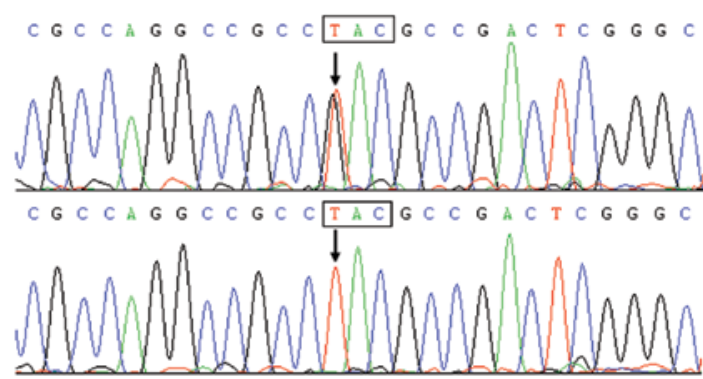

B

Mutant
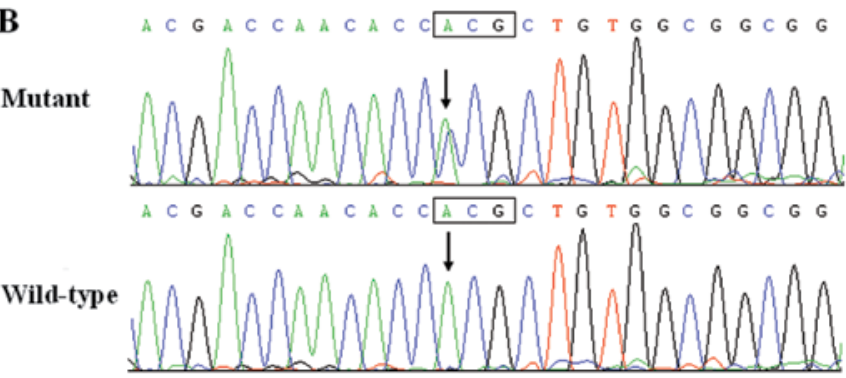

Figure 1. Sequence electropherograms showing the GATA5 mutations in contrast to the corresponding controls. The arrow indicates the heterozygous nucleotides of $\mathrm{A} / \mathrm{G}$ in the proband from family 1 or $\mathrm{A} / \mathrm{C}$ in the proband from family 2 (mutant); or the homozygous nucleotides of A/A in the corresponding control individuals (wild-type). The rectangle represents the nucleotides constituting a codon of GATA5.

Alignment of multiple GATA5 protein sequence. As shown in Fig. 4, a cross-species alignment of multiple GATA5 protein sequences demonstrated that the affected amino acids of p.Y16 and p.T252 were completely conserved evolutionarily, suggesting that the amino acids are functionally important.

Causative potential of GATA5 sequence variations. The GATA5 sequence variations of c.46T $>\mathrm{G}$ and c.754A $>\mathrm{C}$ were automatically predicted to be disease-causing, with $\mathrm{P}$-values of 0.82270 and 1.00000 , respectively. No SNPs in the altered regions were identified in the MutationTaster database. The two variations were predicted to be probably damaging by the

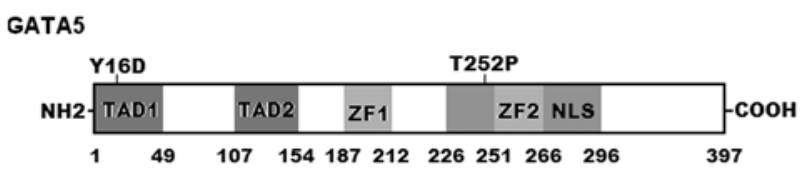

Figure 2. Schematic diagram of GATA5 protein structure with the mutations responsible for congenital bicuspid aortic valve. The mutations associated with congenital bicuspid aortic valve are shown above the structural domains. NH2, amino-terminus; TAD, transcriptional activation domain; $\mathrm{ZF}$, zinc finger; NLS, nuclear localization signal; $\mathrm{COOH}$, carboxyl-terminus.

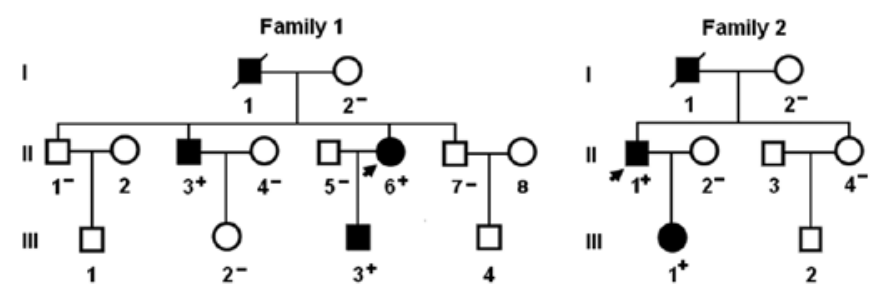

Figure 3. Pedigree structures of the families with congenital bicuspid aortic valve. Families are designated as families 1 and 2, respectively. Family members are identified by generations and numbers. Squares indicate male family members; circles, female members; closed symbols, affected members; open symbols, unaffected members; symbols with a slash, the deceased members; arrows, probands; '+', carriers of the heterozygous mutations; and '-, non-carriers.

software PolyPhen-2, with the same score of 1.000 (sensitivity: 0.00; specificity: 1.00 )

Reduced transcriptional activity of the GATA5 mutants. As shown in Fig. 5, the wild-type GATA5, the Y16D-mutant, and the T252P-mutant GATA5 activated the ANF promoter by $~ 12-$, $\sim 6$ - and $\sim 3$-fold, respectively. When wild-type GATA5 was coexpressed with the same amount of Y16D- or T252P-mutant GATA5, the induced activation of the ANF promoter was $\sim 9$ - or $\sim 5$-fold. These results suggest that the two GATA5 mutants are associated with significantly reduced transactivational activity compared with their wild-type counterpart. 


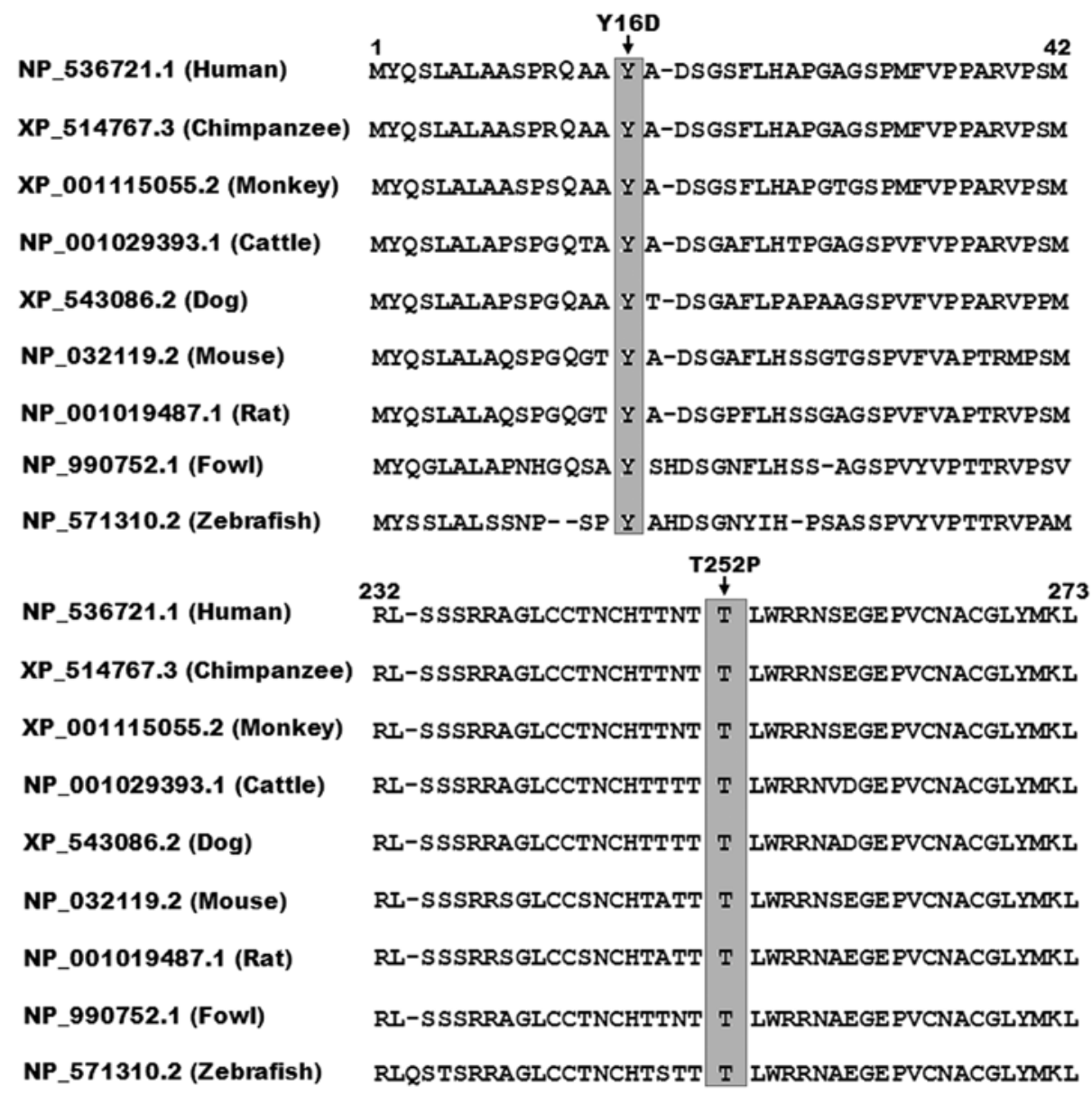

Figure 4. Multiple alignments of GATA5 protein sequences among species. The altered amino acids of p.Q113 and p.T252 are highly conserved evolutionarily across various species.

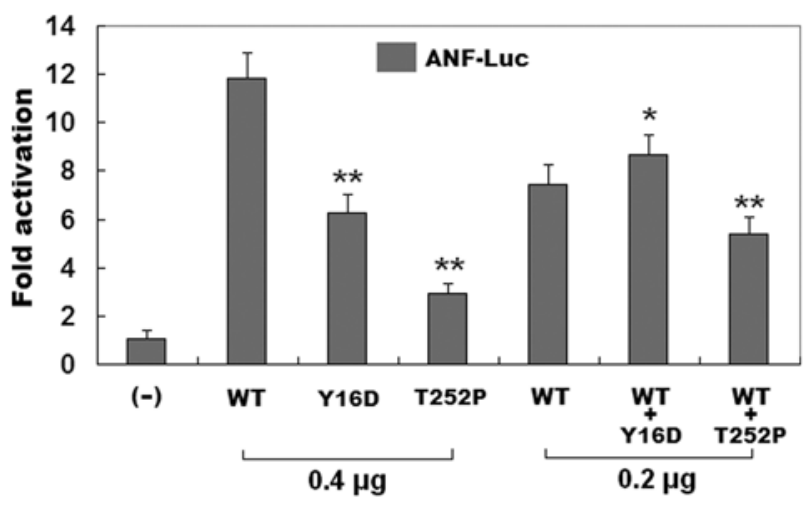

Figure 5. Functional defects of GATA5 resulted from mutations. Activation of the ANF-luciferase reporter in cultured HEK-293 cells by wild-type GATA5 (WT) or mutant (Q13R or T252P), alone or in combination, showed significantly reduced transcriptional activity by mutant proteins. Experiments were performed in triplicate and means \pm standard deviations is shown. ${ }^{* *} \mathrm{P}<0.005$ and ${ }^{*} \mathrm{P}<0.05$, when compared with wild-type GATA5.

\section{Discussion}

In the current study, the novel heterozygous mutations in GATA5, p.Y16D and p.T252P, were identified in two unrelated families with BAV. In each family, the mutant allele was present in all the affected family members, but absent in the unaffected relatives examined and 400 referral chromosomes from an ethnically-matched control population. A cross-species alignment of GATA5 amino acid sequences demonstrated that the altered amino acids were completely conserved evolutionarily. The p.Y16D and p.T252P variations were predicted to be pathogenic mutations, and the functional analysis revealed that the GATA5 mutant proteins were consistently associated with significantly reduced transcriptional activity. Therefore, it is likely that functionally impaired GATA5 contributes to BAV in these families. To the best of our knowledge, this is the first study to associate GATA5 loss-of-function mutations with enhanced susceptibility to BAV in humans.

At present, six members (GATA1-6) of the GATA transcription factor family have been identified in vertebrate. GATA1-3 are important regulators of hematopoietic stem cells and some ectodermal derivatives, whereas GATA4-6 are associated with cardiogenesis and the formation of a subset of endoderm-derived tissues $(32,33)$. The human GATA5 gene was mapped on chromosome $20 \mathrm{q} 13.33$ by fluorescence in situ hybridization, which encodes for a protein of 397 amino acids (40). By alignment of GATA5 with GATA4, the structural domains of GATA5 protein are predicted to encompass two transcriptional activation domains (TAD1, amino acids 1-49 and TAD2, amino acids 107-154), two adjacent zinc fingers (ZF1, amino acids 187-212 and ZF2, amino acids 242-266), which comprise the DNA-binding domain with a Cys- $\mathrm{X}_{2}$-Cys$\mathrm{X}_{17}$-Cys- $\mathrm{X}_{2}$-Cys consensus (where $\mathrm{X}$ represents any amino 
acid), and one nuclear localization signal (NLS, amino acids 226-396). The two TADs are required for the normal transcriptional activity of GATA5. The C-terminal ZF2 is essential for DNA sequence recognition and binding to the consensus motif (T/A)GATA(A/G), within the promoters of target genes; while the N-terminal ZF1 is responsible for sequence specificity and stability of protein-DNA binding, and both ZFs can also interact directly with other regulatory proteins. The NLS is crucial to the sub-cellular trafficking and nuclear distribution of GATA5 (41). The GATA5 mutations of p.Y16D and p.T252P identified in this study are located in TAD1 and ZF2, respectively, and may be expected to exert an effect on the transcriptional activity of GATA 5 by direct inhibition or interfering with the nuclear localization and specific binding ability of GATA5.

In a previous study, it was substantiated that GATA5 regulates multiple downstream molecules expressed during embryogenesis and cardiac morphogenesis, including ANF, brain natriuretic peptide, $\alpha$ - and $\beta$-myosin heavy chains, and cardiac troponin $\mathrm{C}$ and I (32). Thus, the functional characteristics of the GATA5 mutations may be delineated by analyzing the transcriptional activity of the $A N F$ promoter in tool cells. In this study, the functional effect of the novel p.Y16D and p.T252P mutations of GATA5 identified in our familial BAV patients were explored by a transcriptional activity assay and the results revealed a significantly reduced transcriptional activation of the $A N F$ promoter. These data suggest that genetically compromised GATA5 is potentially an alternative molecular mechanism of BAV.

The relationship between GATA5 variants and human BAV was previously investigated. Padang et al screened the coding regions and splice signal sequences of the GATA5 gene in 100 unrelated BAV patients, and found four rare non-synonymous variations within the GATA5 transcriptional activation domains, i.e., p.Q3R, p.S19W, p.Y142H and p.G166S, in 4 of 100 unrelated patients, respectively, with a mutational prevalence of $4 \%$ (37). However, the functional roles of these GATA5 variations remain to be determined. Foffa and colleagues screened by direct sequencing all the coding exons including adjacent intronic as well as 5'- and 3'-untranslated of GATA5 in a cohort of 11 index patients with familial BAV, however, no pathogenetic mutation was identified in GATA (21). The discrepancy in the mutational prevalence of these reports including the present study may be partially explained by different sample size and ethnicity.

It has been validated in animals that genetically defective GATA5 predisposes to congenital cardiovascular defects. In zebrafish, the targeted disruption of GATA5 led to embryonic lethality due to defects in endocardial and myocardial differentiation and migration, a phenotype similar to cardia bifida of GATA4-null zebrafish (43). In mice, GATA5 knockout led to partially penetrant $\mathrm{BAV}$, with a penetrance of $25 \%$, and endocardial cell-specific inactivation of GATA5 resulted in BAV, similar to that observed in GATA5-null mice (31). Furthermore, the mice that were compound heterozygous for GATA5 and GATA4 or for GATA5 and GATA6 knockout died embryonically or perinatally due to severe defects of the outflow tract development including double outlet right ventricle and ventricular septal defect (30). These experimental results emphasize the notable sensitivity of the developing cardiovascular system to the levels of GATA4, GATA5 and GATA6, and indicate that these GATA factors may act cooperatively to regulate some target genes.

Of note, ventricular septal defect and atrial fibrillation were documented in two BAV patients harboring the p.Y16D mutation of GATA5. Similar to our findings, GATA5 has been previously reported to be involved in various congenital heart diseases as well as atrial fibrillation $(38,39,42)$. Additionally, the GATA family members GATA4 and GATA6 have an expression profile and functional characteristics that overlap with those of GATA5, and a long list of mutations in GATA4 and GATA6 have also been connected with a large variety of congenital cardiovascular deformations and atrial fibrillation (44-77). These findings support that the transcription factors of the GATA family are pivotal for the cardiovascular morphogenesis.

In conclusion, to the best of our knowledge, this study provides the first genetic evidence for the association of functionally compromised GATA5 with increased vulnerability to BAV, highlighting the role of a GATA signaling pathway in BAV and other developmental cardiovascular malformations, and suggesting the potential implications for genetic counseling and clinical care of the families presenting with BAV.

\section{Acknowledgements}

The authors would like to thank the participants for their dedication to the study. This study was supported in part by grants from the National Natural Science Fund of China (81070153, 81270161 and 81271927), the Personnel Development Foundation of Shanghai, China (2010019), the Natural Science Fund of Shanghai, China (10ZR1428000), and the Key Program of Basic Research of Shanghai, China (10JC1414002).

\section{References}

1. Go AS, Mozaffarian D, Roger VL, Benjamin EJ, Berry JD, Borden WB, Bravata DM, Dai S, Ford ES, Fox CS, Franco S, Fullerton HJ, Gillespie C, Hailpern SM, Heit JA, Howard VJ, Huffman MD, Kissela BM, Kittner SJ, Lackland DT, Lichtman JH, Lisabeth LD, Magid D, Marcus GM, Marelli A, Matchar DB, McGuire DK, Mohler ER, Moy CS, Mussolino ME, Nichol G, Paynter NP, Schreiner PJ, Sorlie PD, Stein J, Turan TN, Virani SS, Wong ND, Woo D and Turner MB; American Heart Association Statistics Committee and Stroke Statistics Subcommittee: Heart disease and stroke statistics-2013 update: a report from the American Heart Association. Circulation 127: e6-e245, 2013.

2 . Roberts WC: The congenitally bicuspid aortic valve. A study of 85 autopsy cases. Am J Cardiol 26: 72-83, 1970.

3. Ward C: Clinical significance of the bicuspid aortic valve. Heart 83: 81-85, 2000.

4. Larson EW and Edwards WD: Risk factors for aortic dissection: a necropsy study of 161 cases. Am J Cardiol 53: 849-855, 1984.

5. Basso C, Boschello M, Perrone C, Mecenero A, Cera A, Bicego D, Thiene $\mathrm{G}$ and De Dominicis E: An echocardiographic survey of primary school children for bicuspid aortic valve. Am J Cardiol 93: 661-663, 2004.

6. Tutar E, Ekici F, Atalay S and Nacar N: The prevalence of bicuspid aortic valve in newborns by echocardiographic screening. Am Heart J 150: 513-515, 2005.

7. Siu SC and Silversides CK: Bicuspid aortic valve disease. J Am Coll Cardiol 55: 2789-2800, 2010.

8. Fedak PW, Verma S, David TE, Leask RL, Weisel RD and Butany J: Clinical and pathophysiological implications of a bicuspid aortic valve. Circulation 106: 900-904, 2002.

9. Tadros TM, Klein MD and Shapira OM: Ascending aortic dilatation associated with bicuspid aortic valve: pathophysiology, molecular biology, and clinical implications. Circulation 119: 880-890, 2009. 
10. Alegret JM, Ligero C, Vernis JM, Beltrán-Debón R, Aragonés G, Duran I, Palazón O and Hernández-Aparicio A: Factors related to the need for surgery after the diagnosis of bicuspid aortic valve: one center's experience under a conservative approach. Int J Med Sci 10: 176-182, 2013.

11. Baig W: Endocarditis on the bicuspid aortic valve: what's the risk? Heart 96: 1689-1690, 2010.

12. Mack G and Silberbach M: Aortic and pulmonary stenosis. Pediatr Rev 21: 79-85, 2000.

13. Cripe L, Andelfinger G, Martin LJ, Shooner K and Benson DW: Bicuspid aortic valve is heritable. J Am Coll Cardiol 44: 138-143, 2004.

14. Michelena HI, Khanna AD, Mahoney D, Margaryan E, Topilsky Y, Suri RM, Eidem B, Edwards WD, Sundt TM III and Enriquez-Sarano M: Incidence of aortic complications in patients with bicuspid aortic valves. JAMA 306: 1104-1112, 2011

15. Armstrong EJ and Bischoff J: Heart valve development: endothelial cell signaling and differentiation. Circ Res 95: 459-470, 2004.

16. Combs MD and Yutzey KE: Heart valve development: regulatory networks in development and disease. Circ Res 105: 408-421, 2009.

17. Garg V, Muth AN, Ransom JF, Schluterman MK, Barnes R, King IN, Grossfeld PD and Srivastava D: Mutations in NOTCH1 cause aortic valve disease. Nature 437: 270-274, 2005

18. Martin LJ, Ramachandran V, Cripe LH, Hinton RB Andelfinger G, Tabangin M, Shooner K, Keddache M and Benson DW: Evidence in favor of linkage to human chromosomal regions $18 \mathrm{q}, 5 \mathrm{q}$ and $13 \mathrm{q}$ for bicuspid aortic valve and associated cardiovascular malformations. Hum Genet 121: 275-284, 2007.

19. Mohamed SA, Aherrahrou Z, Liptau H, Erasmi AW, Hagemann C, Wrobel S, Borzym K, Schunkert H, Sievers HH and Erdmann J: Novel missense mutations (p.T596M and p.P1797H) in NOTCH1 in patients with bicuspid aortic valve. Biochem Biophys Res Commun 345: 1460-1465, 2006.

20. McKellar SH, Tester DJ, Yagubyan M, Majumdar R, Ackerman MJ and Sundt TM III: Novel NOTCH1 mutations in patients with bicuspid aortic valve disease and thoracic aortic aneurysms. J Thorac Cardiovasc Surg 134: 290-296, 2007.

21. Foffa I, Ait Alì L, Panesi P, Mariani M, Festa P, Botto N, Vecoli C and Andreassi MG: Sequencing of NOTCH1, GATA5, TGFBR1 and TGFBR2 genes in familial cases of bicuspid aortic valve. BMC Med Genet 14: 44, 2013.

22. Andelfinger G, Tapper AR, Welch RC, Vanoye CG, George AL Jr and Benson DW: KCNJ2 mutation results in Andersen syndrome with sex-specific cardiac and skeletal muscle phenotypes. Am J Hum Genet 71: 663-668, 2002.

23. Girdauskas E, Schulz S, Borger MA, Mierzwa M and Kuntze T: Transforming growth factor-beta receptor type II mutation in a patient with bicuspid aortic valve disease and intraoperative aortic dissection. Ann Thorac Surg 14: e70-e71, 2011.

24. Beffagna G, Cecchetto A, Dal Bianco L, Lorenzon A, Angelini A, Padalino M, Vida V, Bhattacharya S, Stellin G, Rampazzo A and Daliento L: R25C mutation in the NKX2.5 gene in Italian patients affected with non-syndromic and syndromic congenital heart disease. J Cardiovasc Med (Hagerstown) 14: 582-586, 2013

25. Reiter JF, Alexander J, Rodaway A, Yelon D, Patient R, Holder N and Stainier DY: Gata5 is required for the development of the heart and endoderm in zebrafish. Genes Dev 13: 2983-2995, 1999.

26. Nemer G and Nemer M: Cooperative interaction between GATA5 and NF-ATc regulates endothelial-endocardial differentiation of cardiogenic cells. Development 129: 4045-4055, 2002.

27. Stennard FA, Costa MW, Elliott DA, Rankin S, Haast SJ, Lai D, McDonald LP, Niederreither K, Dolle P, Bruneau BG, Zorn AM and Harvey RP: Cardiac T-box factor Tbx20 directly interacts with Nkx2-5, GATA4, and GATA5 in regulation of gene expression in the developing heart. Dev Biol 262: 206-224, 2003.

28. Haworth KE, Kotecha S, Mohun TJ and Latinkic BV: GATA4 and GATA5 are essential for heart and liver development in Xenopus embryos. BMC Dev Biol 8: 74, 2008.

29. Singh MK, Li Y, Li S, Cobb RM, Zhou D, Lu MM, Epstein JA, Morrisey EE and Gruber PJ: Gata4 and Gata5 cooperatively regulate cardiac myocyte proliferation in mice. J Biol Chem 285 : $1765-72,2010$

30. Laforest B and Nemer M: GATA5 interacts with GATA4 and GATA6 in outflow tract development. Dev Biol 358: 368-378, 2011.

31. Laforest B, Andelfinger G and Nemer M: Loss of Gata5 in mice leads to bicuspid aortic valve. J Clin Invest 121: 2876-2887, 2011
32. Pikkarainen S, Tokola H, Kerkelä R and Ruskoaho H: GATA transcription factors in the developing and adult heart. Cardiovasc Res 63: 196-207, 2004.

33. Peterkin T, Gibson A, Loose M and Patient R: The roles of GATA-4, -5 and -6 in vertebrate heart development. Semin Cell Dev Bio 16: 83-94, 2005

34. Wei D, Bao H, Zhou N, Zheng GF, Liu XY and Yang YQ: GATA5 loss-of-function mutation responsible for the congenital ventriculoseptal defect. Pediatr Cardiol 34: 504-511, 2013.

35. Jiang JQ, Li RG, Wang J, Liu XY, Xu YJ, Fang WY, Chen XZ, Zhang W, Wang XZ and Yang YQ: Prevalence and spectrum of GATA5 mutations associated with congenital heart disease. Int J Cardiol 165: 570-573, 2013

36. Wei D, Bao H, Liu XY, Zhou N, Wang Q, Li RG, Xu YJ and Yang YQ: GATA5 loss-of-function mutations underlie tetralogy of fallot. Int J Med Sci 10: 34-42, 2013.

37. Padang R, Bagnall RD, Richmond DR, Bannon PG and Semsarian C: Rare non-synonymous variations in the transcriptional activation domains of GATA5 in bicuspid aortic valve disease. J Mol Cell Cardiol 53: 277-281, 2012.

38. Yang YQ, Wang J, Wang XH, Wang Q, Tan HW, Zhang M, Shen FF, Jiang JQ, Fang WY and Liu X: Mutational spectrum of the GATA5 gene associated with familial atrial fibrillation. Int J Cardiol 157: 305-307, 2012

39. Wang XH, Huang CX, Wang Q, Li RG, Xu YJ, Liu X, Fang WY and Yang YQ: A novel GATA5 loss-of-function mutation underlies lone atrial fibrillation. Int J Mol Med 31: 43-50, 2013.

40. Nemer G, Qureshi ST, Malo D and Nemer M: Functional analysis and chromosomal mapping of Gata5, a gene encoding a zinc finger DNA-binding protein. Mamm Genome 10: 993-999, 1999

41. Brewer A and Pizzey J: GATA factors in vertebrate heart development and disease. Expert Rev Mol Med 15: 1-20, 2006.

42. Gu JY, Xu JH, Yu H and Yang YQ: Novel GATA5 loss-offunction mutations underlie familial atrial fibrillation. Clinics (Sao Paulo) 67: 1393-1399, 2012.

43. Heicklen-Klein A, McReynolds LJ and Evans T: Using the zebrafish model to study GATA transcription factors. Semin Cell Dev Biol 16: 95-106, 2005.

44. Garg V, Kathiriya IS, Barnes R, Schluterman MK, King IN, Butler CA, Rothrock CR, Eapen RS, Hirayama-Yamada K, Joo K, Matsuoka R, Cohen JC and Srivastava D: GATA4 mutations cause human congenital heart defects and reveal an interaction with TBX5. Nature 424: 443-447, 2003.

45. Okubo A, Miyoshi O, Baba K, Takagi M, Tsukamoto K, Kinoshita A, Yoshiura K, Kishino T, Ohta T, Niikawa N and Matsumoto N: A novel GATA4 mutation completely segregated with atrial septal defect in a large Japanese family. J Med Genet 41: e97, 2004.

46. Sarkozy A, Conti E, Neri C, D'Agostino R, Digilio MC, Esposito G, Toscano A, Marino B, Pizzuti A and Dallapiccola B: Spectrum of atrial septal defects associated with mutations of NKX2.5 and GATA4 transcription factors. J Med Genet 42: e16, 2005.

47. Hirayama-Yamada K, Kamisago M, Akimoto K, Aotsuka H, Nakamura Y, Tomita H, Furutani M, Imamura S, Takao A, Nakazawa M and Matsuoka R: Phenotypes with GATA4 or NKX2.5 mutations in familial atrial septal defect. Am J Med Genet A 135: 47-52, 2005.

48. Reamon-Buettner SM and Borlak J: GATA4 zinc finger mutations as a molecular rationale for septation defects of the human heart. J Med Genet 42: e32, 2005.

49. Nemer G, Fadlalah F, Usta J, Nemer M, Dbaibo G, Obeid M and Bitar F: A novel mutation in the GATA4 gene in patients with Tetralogy of Fallot. Hum Mutat 27: 293-294, 2006.

50. Tomita-Mitchell A, Maslen CL, Morris CD, Garg V and Goldmuntz E: GATA4 sequence variants in patients with congenital heart disease. J Med Genet 44: 779-783, 2007.

51. Rajagopal SK, Ma Q, Obler D, Shen J, Manichaikul A, TomitaMitchell A, Boardman K, Briggs C, Garg V, Srivastava D, Goldmuntz E, Broman KW, Benson DW, Smoot LB and Pu WT: Spectrum of heart disease associated with murine and human GATA4 mutation. J Mol Cell Cardiol 43: 677-685, 2007.

52. Zhang W, Li X, Shen A, Jiao W, Guan X and Li Z: GATA4 mutations in 486 Chinese patients with congenital heart disease. Eur J Med Genet 51: 527-535, 2008.

53. Hamanoue H, Rahayuningsih SE, Hirahara Y, Itoh J, Yokoyama U, Mizuguchi T, Saitsu H, Miyake N, Hirahara F and Matsumoto N: Genetic screening of 104 patients with congenitally malformed hearts revealed a fresh mutation of GATA4 in those with atrial septal defects. Cardiol Young 19: 482-485, 2009. 
54. Chen MW, Pang YS, Guo Y, Pan JH, Liu BL, Shen J and Liu TW: GATA4 mutations in Chinese patients with congenital cardiac septal defects. Pediatr Cardiol 31: 85-89, 2010.

55. Chen Y, Mao J, Sun Y, Zhang Q, Cheng HB, Yan WH, Choy KW and $\mathrm{Li} \mathrm{H}$ : A novel mutation of GATA4 in a familial atrial septal defect. Clin Chim Acta 411: 1741-1745, 2010.

56. Butler TL, Esposito G, Blue GM, Cole AD, Costa MW, Waddell LB, Walizada G, Sholler GF, Kirk EP, Feneley M, Harvey RP and Winlaw DS: GATA4 mutations in 357 unrelated patients with congenital heart malformation. Genet Test Mol Biomarkers 14: 797-802, 2010.

57. Salazar M, Consoli F, Villegas V, Caicedo V, Maddaloni V, Daniele P, Caianiello G, Pachón S, Nuñez F, Limongelli G, Pacileo G, Marino B, Bernal JE, De Luca A and Dallapiccola B: Search of somatic GATA4 and NKX2.5 gene mutations in sporadic septal heart defects. Eur J Med Genet 54: 306-309, 2011.

58. Liu XY, Wang J, Zheng JH, Bai K, Liu ZM, Wang XZ, Liu X, Fang WY and Yang YQ: Involvement of a novel GATA4 mutation in atrial septal defects. Int J Mol Med 28: 17-23, 2011.

59. Wang J, Fang M, Liu XY, Xin YF, Liu ZM, Chen XZ, Wang XZ, Fang WY, Liu X and Yang YQ: A novel GATA4 mutation responsible for congenital ventricular septal defects. Int J Mol Med 28: 557-564, 2011

60. Yang YQ, Li L, Wang J, Liu XY, Chen XZ, Zhang W, Wang XZ, Jiang JQ, Liu X and Fang WY: A novel GATA4 loss-of-function mutation associated with congenital ventricular septal defect. Pediatr Cardiol 33: 539-546, 2012.

61. Granados-Riveron JT, Pope M, Bu'lock FA, Thornborough C, Eason J, Setchfield K, Ketley A, Kirk EP, Fatkin D, Feneley MP Harvey RP and Brook JD: Combined mutation screening of NKX2-5, GATA4, and TBX5 in congenital heart disease: multiple heterozygosity and novel mutations. Congenit Heart Dis 7: 151-159, 2012.

62. Yang YQ, Wang J, Liu XY, Chen XZ, Zhang W, Wang XZ, Liu $X$ and Fang WY: Novel GATA4 mutations in patients with congenital ventricular septal defects. Med Sci Monit 18: CR344-CR350, 2012.

63. Wang E, Sun S, Qiao B, Duan W, Huang G, An Y, Xu S, Zheng Y, $\mathrm{Su} \mathrm{Z}, \mathrm{Gu} X$, Jin $\mathrm{L}$ and Wang H: Identification of functional mutations in GATA4 in patients with congenital heart disease. PLoS One 8: e62138, 2013.

64. Li RG, Li L, Qiu XB, Yuan F, Xu L, Li X, Xu YJ, Jiang WF, Jiang JQ, Liu X, Fang WY, Zhang M, Peng LY, Qu XK and Yang YQ: GATA4 loss-of-function mutation underlies familial dilated cardiomyopathy. Biochem Biophys Res Commun 439. 591-596, 2013.
65. Yang YQ, Gharibeh L, Li RG, Xin YF, Wang J, Liu ZM, Qiu XB, Xu YJ, Xu L, Qu XK, Liu X, Fang WY, Huang RT, Xue S and Nemer G: GATA4 loss-of-function mutations underlie familial tetralogy of fallot. Hum Mutat 34: 1662-1671, 2013.

66. Jiang JQ, Shen FF, Fang WY, Liu X and Yang YQ: Novel GATA4 mutations in lone atrial fibrillation. Int J Mol Med 28: 1025-1032, 2011.

67. Yang YQ, Wang MY, Zhang XL, Tan HW, Shi HF, Jiang WF, Wang XH, Fang WY and Liu X: GATA4 loss-of-function mutations in familial atrial fibrillation. Clin Chim Acta 412: 1825-1830, 2011

68. Wang J, Sun YM and Yang YQ: Mutation spectrum of the GATA4 gene in patients with idiopathic atrial fibrillation. Mol Biol Rep 39: 8127-8135, 2012.

69. Kodo K, Nishizawa T, Furutani M, Arai S, Yamamura E, Joo K, Takahashi T, Matsuoka R and Yamagishi H: GATA6 mutations cause human cardiac outflow tract defects by disrupting semaphorin-plexin signaling. Proc Natl Acad Sci USA 106: 13933-13938, 2009.

70. Lin X, Huo Z, Liu X, Zhang Y, Li L, Zhao H, Yan B, Liu Y, Yang Y and Chen YH: A novel GATA6 mutation in patients with tetralogy of Fallot or atrial septal defect. J Hum Genet 55: 662-667, 2010.

71. Maitra M, Koenig SN, Srivastava D and Garg V: Identification of GATA6 sequence variants in patients with congenital heart defects. Pediatr Res 68: 281-285, 2010

72. Zheng GF, Wei D, Zhao H, Zhou N, Yang YQ and Liu XY: A novel GATA6 mutation associated with congenital ventricular septal defect. Int J Mol Med 29: 1065-1071, 2012.

73. Wang J, Luo XJ, Xin YF, Liu Y, Liu ZM, Wang Q, Li RG, Fang WY, Wang XZ and Yang YQ: Novel GATA6 mutations associated with congenital ventricular septal defect or tetralogy of fallot. DNA Cell Biol 31: 1610-1617, 2012.

74. Huang RT, Xue S, Xu YJ and Yang YQ: Somatic mutations in the GATA6 gene underlie sporadic tetralogy of Fallot. Int J Mol Med 31: 51-58, 2013

75. Yang YQ, Wang XH, Tan HW, Jiang WF, Fang WY and Liu X: Prevalence and spectrum of GATA6 mutations associated with familial atrial fibrillation. Int J Cardiol 155: 494-496, 2012.

76. Yang YQ, Li L, Wang J, Zhang XL, Li RG, Xu YJ, Tan HW, Wang XH, Jiang JQ, Fang WY and Liu X: GATA6 loss-offunction mutation in atrial fibrillation. Eur J Med Genet 55: 520-526, 2012

77. Li J, Liu WD, Yang ZL and Yang YQ: Novel GATA6 loss-offunction mutation responsible for familial atrial fibrillation. Int $J$ Mol Med 30: 783-790, 2012. 